This is the postprint (accepted manuscript) version of the article published by Taylor \& Francis in the International Journal of Environmental Analytical Chemistry on December, 10th 2018. Available on-line: http://www.tandfonline.com//10.1080/03067319.2018.1554743

\title{
Assessing Cocaine Use Patterns in the Brazilian Capital by Wastewater-Based Epidemiology
}

Katyeny Manuela da Silva ${ }^{\mathrm{a}}$, José Benito Quintana ${ }^{\mathrm{b}}$, Iria González-Mariño ${ }^{\mathrm{b}}$, Rosario Rodil ${ }^{\mathrm{b}}$, Andrea Donatti Gallassi ${ }^{\mathrm{c}}$, Luciano Chaves Arantes ${ }^{\mathrm{d}}$ and Fernando Fabriz Sodré ${ }^{\text {* }}$

${ }^{a}$ Institute of Chemistry, University of Brasilia, Brasilia, 70910-000, Brazil; ${ }^{b}$ Institute for Food Analysis and Research, Universidade de Santiago de Compostela, Santiago de Compostela, 15782, Spain; ${ }^{c}$ Center of Drugs and Associated Vulnerabilities, University of Brasilia, Ceilândia Campus, 72220-900, Brazil; ${ }^{d}$ Institute of Criminalistics, Department of Technical Police, Brasilia, 70610-907, Brazil

*ffsodre@unb.br 


\title{
Assessing Cocaine Use Patterns in the Brazilian Capital by Wastewater-Based Epidemiology
}

\begin{abstract}
The levels of cocaine (COC) and its metabolites benzoylecgonine (BE) and cocaethylene (COE) in wastewater samples from Brasilia, Brazil, were determined using liquid chromatography coupled to hybrid quadrupole-time-offlight mass spectrometry. The former metabolite was used to estimate cocaine consumption using a country-tuned correction factor that considers BE excretion rates for different routes of administration as well as the fraction of crack users in Brazil. A day-to-day analysis during a week indicates higher cocaine use in weekends with peaks on Sunday in both southern $\left(7385 \pm 121 \mathrm{mg}^{-1 a y}{ }^{-1} 1000\right.$ inhab $\left.^{-1}\right)$ and northern $\left(3566 \pm 171 \mathrm{mg} \mathrm{day}^{-1} 1000\right.$ inhab $\left.^{-1}\right)$ areas of Brasilia. A significant high cocaine use was also observed in the Carnival Day of 2018 $\left(6229 \pm 219 \mathrm{mg} \mathrm{day}^{-1} 1000 \mathrm{inhab}^{-1}\right)$. COE/BE ratios were used to assess COC and alcohol co-consumption since $\mathrm{COE}$ is produced during the co-consumption of both substances. Higher ratios were also observed during the weekend. However, higher ratios on Saturdays rather than Sundays may be explained by the decrease of $\mathrm{BE}$ excretion during the co-consumption with alcohol, which may lead to an underestimation of the cocaine use estimates on Saturdays, as well as by different patterns of co-consumption by powder and crack users, where the latter usually drink lower amounts of alcohol. Our data suggest that only $3 \%$ of cocaine was seized by the local Technical Police during the study.
\end{abstract}

Keywords: wastewater-based epidemiology; cocaine; crack; Brazil; cocaethylene

\section{Introduction}

The Brazilian Federal District (FD) was planned in the nineteen-sixties to house the national capital, Brasilia, a city that is the current centre of executive, legislative and judiciary decisions. Immediately after its foundation, the city provided new well-paid jobs attracting a number of newcomers from different regions of the country, leading to a fast but unsustainable development. Nowadays, Brasilia and its satellite cities account 
for more than 3.0 million inhabitants [1]. Like many Latin American cities, Brasilia has problems with drug trafficking and consumption. Although the recreational poly use of drugs, notably cocaine and alcohol, has been frequently reported [2], Brazil has also faced a spread of crack consumption all over the country in the last decades [3].

The wastewater-based epidemiology (WBE) has been developed in the last years as a novel approach to assess drug use, as well as health and lifestyle habits [4,5]. Briefly, consumed chemicals are totally or partially excreted in urine reaching the sewer system, where selected biomarkers, such as active parent substances or their metabolites, are measured. Thus, a back-calculation that includes information on the sewage flow, the excreted fraction of the biomarker and the population under investigation provides a community-scale information. The WBE approach is already well established in the literature as a complementary tool to estimate cocaine use in a fast way, allowing dynamic investigations concerning the temporal evolution of consumption [6]. It has provided estimates on the use of different licit and illicit substances in many countries [7-12], as well as a better understanding of the user's behaviour in compliance with basic ethical principles $[13,14]$.

Like any other epidemiological data, the information produced by WBE is also susceptible to uncertainties, notably related to the representativeness of the collected samples, to the analytical method employed, to the stability of the biomarkers in sewage, and to population size fluctuations $[15,16]$. An important way to reduce uncertainty and hence improve the reliability of estimates is to choose suitable biomarkers and appropriate parameters for the back-calculation [15].

Cocaine is a potent stimulant drug being one of the most consumed illicit substance in the Americas [17]. The metabolite benzoylecgonine (BE) has been widely used for cocaine use estimates due to its relatively high excretion rate and higher 
stability in sewage samples compared to other COC metabolites [18]. Cocaine is often used as hydrochloride salt powder by an intranasal route of administration being preferentially absorbed through the nostrils [19], while smoked free-base cocaine (crack), is more volatile and quickly reaches the lungs where absorption into the bloodstream is similar to intravenous administration [20]. When cocaine is smoked, BE production rates are decreased and higher amounts of anhydroecgonine methyl ester are formed leading to the formation of anhydroecgonine by enzymatic cleavage and spontaneous chemical hydrolysis [21]. The co-consumption of cocaine and alcohol, a known depressant, is one of the most common association among drug users [22]. Since they affect the central nervous system differently, leading the user to feel sober, the risk of overdose is greater than taking the substances separately [23]. Additionally, alcohol affects the metabolism of COC, increasing the plasma levels of the parent substance and norcocaine, decreasing the amount of $\mathrm{BE}$, and producing the substance cocaethylene (COE) by transesterification mediated by the enzymatic action of a carboxylesterase (hCE1) [24-26]. Consequently, COE can be used to monitor cocaine and alcohol coconsumption as well as the effect of alcohol on the BE levels found in urine and in sewage samples [27].

In order to contribute to the studies of WBE in Brazil, this work aimed to assess the levels of $\mathrm{COC}, \mathrm{BE}$ and $\mathrm{COE}$ in sewage samples collected in two wastewater treatment plants (WWTP) of the Brazilian Capital, Brasilia. The area served by these two WWTP was previously investigated concerning the use of cocaine using the WBE approach [28-30]. For the first time in Brazil, we assess the levels of COE during a dayto-day investigation in order to better understand the co-consumption of cocaine and alcohol [31] and to assess the potential of WBE in the study of users in a community- 
scale investigation. Our findings were also compared with seized data from the local Technical Police.

\section{Experimental}

\subsection{Chemicals}

COC, BE, COE, and their deuterated analogues (COC-d3, BE-d3 and COE-d3) were purchased from Cerilliant (Round Rock, USA) in acetonitrile (ACN) or methanol $(\mathrm{MeOH})$ solutions containing $1.0 \mathrm{mg} \mathrm{mL}^{-1}$ of COC, BE and COE and $0.1 \mathrm{mg} \mathrm{mL}^{-1}$ of their deuterated standards. Individual stock solutions were prepared in $\mathrm{MeOH}$ and kept at $-20{ }^{\circ} \mathrm{C}$ until use. $\mathrm{MeOH}$ and $\mathrm{HPLC}$ grade $\mathrm{ACN}$, formic acid (98-100\%), hydrochloric acid (37\%) were purchased from Merck (Darmstadt, Germany). Ultrapure water was obtained in the laboratory in a Milli-Q Gradient A-10 system (Millipore, Bedford, MA, USA). Strata- $\mathrm{X}^{\circledR}$, disposable cartridges for solid-phase extraction (SPE), containing $200 \mathrm{mg}$ of a polystyrene divinylbenzene sorbent with both hydrophilic and lipophilic properties, were acquired from Phenomenex (Torrance, CA, USA).

\subsection{Study Area and sampling}

Samples were collected at the inlet streams of two domestic WWTPs of the Brazilian Federal District (FD), located in the capital, Brasilia. Figure 1 shows the area covered by each WWTP. The North-Wing WWTP serves a population of almost 145,000 people, while South-Wing WWTP covers an area of the FD with approximately 525,000 inhabitants.

Sampling was carried out in eight consecutive days, from $30^{\text {th }}$ May to $6^{\text {th }}$ June 2017. Samples from $30^{\text {th }}$ May (Tuesday) and $2^{\text {nd }}$ June (Friday) were not collected in the North-Wing WWTP due to logistic difficulties concerning the plant operation. An 
additional sample was collected in this WWTP during the Carnival Day of $2018\left(13^{\text {th }}\right.$ February, Tuesday). The Carnival Holiday is the most popular Brazilian celebration usually starting on Friday and ending on the next Wednesday. During this period, a variety of festive events are accompanied by a lot of music, dancing, and drinking throughout the day [32].

An automatic refrigerated $\left(4^{\circ} \mathrm{C}\right)$ sampler (AS950, $\mathrm{HACH}$, Colorado, USA) was used to collect composite influent samples in flow proportional aliquots during $24 \mathrm{~h}$ periods. Sampling started 12 midnight (12:00 a.m.) and ended at the same hour on the next day. Samples were taken to the laboratory in amber glass bottles every day at 7:00 a.m.

\subsection{Sample Preparation}

Samples were subjected to a SPE procedure developed and validated elsewhere [29]. Briefly, aliquots of $50 \mathrm{~mL}$ of unfiltered samples were acidified to $\mathrm{pH} 2.0$ with a $2.0 \mathrm{~mol}$ $\mathrm{L}^{-1} \mathrm{HCl}$ solution and transferred to individual $60-\mathrm{mL}$ syringe tubes connected in-line to the SPE cartridges. To avoid clogging, laboratory grade glass wool was placed on the top frit of the cartridges. The sorbent phase was conditioned with $6 \mathrm{~mL}$ of a MeOH:ACN mixture (60:40 v/v) followed by $6 \mathrm{~mL}$ of a $\mathrm{pH} 2.0$ ultrapure water. Samples were passed through the cartridges at a flow rate of $3 \mathrm{~mL} \mathrm{~min}^{-1}$ in order to provide adequate contact between the analytes and the sorbent phase. Cartridges were then centrifuged at $4000 \mathrm{rpm}$ for $5 \mathrm{~min}$ to eliminate residual water, dried under a constant stream of $\mathrm{N}_{2}$ for 5 min and kept frozen until the elution step. Then, cartridges were packed in ice in an insulated bag and transported to the analytical chemistry laboratory of the Institute for Food Analyses and Research in Santiago de Compostela (Spain), where analyses were carried out. In Spain, analytes were recovered with $6 \mathrm{~mL}$ of $\mathrm{MeOH}$ into previously cleaned glass tubes and internal standards were added to the 
extracts to compensate for evaporation losses and matrix effects. The eluates were evaporated to dryness at $40^{\circ} \mathrm{C}$ under a $\mathrm{N}_{2}$ flow in a TurboVap ${ }^{\circledR}$ II (Biotage, SE) and the resulting materials were redissolved with $\mathrm{MeOH}$ to a final volume of $0.2 \mathrm{~mL}$.

For all transported samples, elution was carried out within a maximum period of 24h after arrival, except for the sample collected during the carnival day. In this case, sample preparation was carried out solely in Brazil according to the procedure described above. Analytes stability during transport of the cartridges (in-cartridge stability) was investigated in spiked samples $\left(0.4 \mu \mathrm{g} \mathrm{L}^{-1}\right)$ collected in North-Wing WWTP and prepared using the extraction procedure described above. Cartridges were kept protected from light at room temperature $\left(23^{\circ} \mathrm{C}\right)$ for a $24 \mathrm{~h}$ period prior to the elution step. Analytes stability in the wastewater (in-sewer stability) was also investigated using spiked samples $\left(0.4 \mu \mathrm{g} \mathrm{L}^{-1}\right)$ kept under stirring at $23{ }^{\circ} \mathrm{C}$, in the dark, in a refrigerated incubated shaker (SI-600R, Lab Companion Jeio Tech, South Korea) in order to mimic typical conditions expected in the sewer system of Brasilia.

\subsection{Analytes Quantification}

All extracts were analysed by liquid chromatography coupled to a high-resolution hybrid quadrupole-time-of-flight mass spectrometer (LC-QTOF). The exception is made for the Carnival sample and for the samples investigated during stability tests. In this case, analyses were carried out in Brazil using a liquid chromatograph coupled to a triple-quadrupole mass spectrometer. Details on the equipment used in Brazil are given in the Supplemental Material.

The LC-QTOF system consisted of a 1200 Series HPLC chromatographic system (Agilent Technologies, Santa Clara, USA) with a binary pump, an autosampler and a thermostatted column compartment coupled to a 6520 Series QTOF system 
(Agilent Technologies, Santa Clara, USA) with a Dual ESI source operated in positive mode with a capillary voltage of $4.0 \mathrm{kV}$.

Optimal chromatographic parameters were selected by varying the column temperature, the gradient flow rate and composition. The mobile phase consisted of a $0.1 \%$ formic acid solution in ultrapure water as the aqueous phase and $\mathrm{MeOH}$ with formic acid $(0.1 \%)$ as the organic phase. Formic acid was used to improve ionization and the intensity of analytical signals. Separation was performed in a Zorbax SB-Aq C18 column $(150 \times 4.6 \mathrm{~mm}$ I.D. $5.0 \mu \mathrm{m}$ particle size $)$ obtained from Agilent at $40{ }^{\circ} \mathrm{C}$ with gradient elution $(300 \mu \mathrm{L} / \mathrm{min})$ by increasing the organic phase $(20-50 \%)$ in $3 \mathrm{~min}$, followed by an increase to $100 \%$ in $0.1 \mathrm{~min}$ and by keeping this composition constant for $4 \mathrm{~min}$. After readjusting to the initial conditions, the system was re-equilibrated for 6 min. The injection volume was $2 \mu \mathrm{L}$.

Table 1 presents QTOF parameters used for identification and quantification purposes. For each analyte, quantification in the MS mode was achieved using the precursor ion, i. e., the protonated molecular ion $[\mathrm{M}+\mathrm{H}]^{+}$extracted with a mass window of $20 \mathrm{ppm}$ on order to obtain the narrow-window extracted ion chromatogram (nwXIC). A 5 ppm tolerance from the theoretical mass was stablished as criteria for positive identification. Furthermore, at least one product ion produced in the collision cell was selected for each analyte in the MS/MS mode for confirmation purposes. Fragmentor voltage was set at $140 \mathrm{~V}$, while entrance potential and collision energy were set as 65 and $20 \mathrm{eV}$, respectively. Two reference ions $(\mathrm{m} / \mathrm{z} 922.0097$ and $\mathrm{m} / \mathrm{z} 121.0508)$ were continuously used to recalibrate the QTOF system in order to maintain the mass accuracy as indicated by the manufacturer.

Quantification was carried out by internal standard calibration using, at least, ten-points analytical curves previously tested for the homogeneity of variances by the 
Cochran test. Quantification parameters, as well as the limits of quantification and detection, are shown in the Supplemental Material. Matrix effects and recovery efficiency were investigated according to a procedure proposed to assess the overall efficiency of the method [33]. In this case, experiments were performed under three different conditions in order to calculate the efficiency of the method $(E f)$ as shown in equation 1.

$$
E f=\frac{R_{1}-R_{2}}{R_{3}} \times 100
$$

The efficiency of the method was evaluated during the in-cartridge stability tests, since cartridges were transported for $24 \mathrm{~h}$. Thus, spiked wastewater samples, in triplicates, were passed through SPE cartridges (R1) while non-spiked wastewater samples, also in triplicates, were submitted to the same procedure (R2). After extraction, all cartridges were left at room temperature $\left(23{ }^{\circ} \mathrm{C}\right)$ for $24 \mathrm{~h}$ prior to the elution step. Three aliquots of $\mathrm{MeOH}$ were also fortified with a mix of the analytical standards (R3).

\section{Results and discussion}

\subsection{Analytical Performance}

Analytes stability in WBE studies may be assessed by in-sewer and in-sample tests, as pointed out by McCall et al. [34] reviewing the stability of illicit drugs in sewers and wastewater samples. According to the authors, sample storage is the most important aspect to in-sample stability of analytes. In this case, the extraction and storage of the analytes in SPE cartridges may be an alternative approach to keep them stable up to six 
weeks in a temperature of $-20{ }^{\circ} \mathrm{C}$. In the present work, in-sample stability was performed to evaluate possible analyte losses associated with the transport of SPE cartridges, which could not be kept under low temperatures. We prefer to denominate these tests as in-cartridges, in order to differentiate them from other in-sample stability tests which may involve sample preparation, preservation and storage.

During the in-cartridge stability tests, small analyte losses were noticed during the transport period at room temperature. In this case, the efficiency of the method was higher for $\mathrm{COC}(80 \pm 8 \%)$, followed by $\mathrm{BE}(77 \pm 10 \%)$ and $\operatorname{COE}(71 \pm 9 \%)$. The concentration of the analytes in the samples was then corrected using $E f$ values.

In-sewer stability tests aimed to investigate possible transformations of the target analytes during their transport through the sewer system In-sewer stability experiments should consider and mimic all relevant aspects that may occur in sewer, such as the nature of the raw material, the formation of biofilms on the sewer walls, sediments, and the sewer atmosphere [34]. However, most studies, including the present one, investigated the stability of analytes in the raw sewage over a predetermined period of time, under controlled temperature and $\mathrm{pH}$ conditions. As Brazil is located under tropical climate, in-sewer stability tests are indispensable to verify the stability of the analytes under local temperature conditions. It is important to point out that the average temperature in Brasília does not change significantly during the year, varying between 19 and $23{ }^{\circ} \mathrm{C}$. Table 2 portrays the results obtained in the present work as well as previous results obtained in the literature.

Stability results found in this work for COC, BE and COE showed the same behaviour than previous works, where concentrations of BE increase while a slight decrease in the levels of COC and COE is noticed. Devault et al. [38] investigate insewer stability of $\mathrm{COC}$ and $\mathrm{BE}$ under a tropical context, where sewage may reach 
temperatures of about $31^{\circ} \mathrm{C}$. Regardless of the temperature, authors observe a relatively high COC degradation (80\%) under pH 6.5 and 7.6 after 24 In order to avoid further problems related to the stability of target analytes in the wastewater, the use of a refrigerated autosampler is essential considering that wastewater composite samples are commonly obtained during a relatively long period (12 to $24 \mathrm{~h}$ ). These findings also evidenced the need for a quick sample preparation and the necessity of preservation techniques when the sample is being collected for periods longer than $24 \mathrm{~h}$ without proper refrigeration. Simple techniques, such sample acidification, may be adopted to improve stability of analytes for a longer period $[28,34]$. The work carried out by Devault et al.[38] also shows higher in-sewer stability of COC and BE under acidic conditions ( $\mathrm{pH} 5)$.

\subsection{Analytes Concentrations and Cocaine Use Estimates}

Table 3 portrays the concentration of the investigated analytes in the sewage samples collected in this work.

$\mathrm{BE}$ was the analyte detected at higher concentrations in the samples, varying from $1659 \pm 146$ to $8559 \pm 141 \mathrm{ng} \mathrm{L}^{-1}$, followed by COC $\left(835 \pm 58\right.$ to $\left.1983 \pm 40 \mathrm{ng} \mathrm{L}^{-1}\right)$ and COE $\left(<14\right.$ to $\left.422 \pm 44 \mathrm{ng} \mathrm{L}^{-1}\right)$. The highest BE concentration was obtained in the sample collected in the Sunday ( $4^{\text {th }}$ June 2017 ) at the South-Wing WWTP, followed by the sample collected in the Carnival Holiday of $2018\left(5920 \pm 208 \mathrm{ng} \mathrm{L}^{-1}\right)$ at the North-Wing WWTP. In the latter date, COE level was the highest among the other days investigated. As cocaine is often consumed together with alcohol, significant concentrations of the metabolite COE may be a preliminary evidence on the co-consumption of drugs. It is estimated that a high proportion of cocaine users (varying from 50 to $90 \%$ ) may consume cocaine simultaneously to ethanol [39] leading to the excretion of COE. In Table 3, higher COE levels are depicted in the Carnival Day sample together with the 
samples collected during the weekend. During the weekdays, concentrations of this metabolite were lower, in some cases below LOD (12 $\left.\mathrm{ng} \mathrm{L}^{-1}\right)$ or LOQ.

Cocaine use estimates were assessed using concentration data obtained from its major and more stable metabolite in sewage samples, BE [40]. COC levels are not used because it is minimally released in its unchanged form (1-15\%) [16]. Also, overestimated data may be generated as the unchanged form can eventually be disposed (accidentally or not) in the sewer systems. Equation 2 shows how to estimate the consumption $(C)$ of cocaine, in $\mathrm{mg} \mathrm{day}^{-1} 1000$ inhabitants $^{-1}$, using the concentration $(c)$ of BE $\left(\mathrm{mg} \mathrm{L}^{-1}\right)$, the volumetric flow $\left(Q_{\mathrm{V}}\right)$ of the influent sewage $\left(\mathrm{L} \mathrm{day}^{-1}\right)$, a correction factor $(f)$ and the number of inhabitants (inhab) served by the WWTP [18].

$$
C=\frac{c \times Q_{\mathrm{V}} \times f}{\text { inhab }} \times 1000
$$

A $f$ value of 2.33 was firstly proposed by Zuccato et al. [41] using available pharmacokinetic data indicating that $45 \%$ of the consumed cocaine (notably via intranasal) was metabolized and excreted in urine as BE. Thus, by dividing the molecular weight ratio COC/BE (303/289) by 0.45 , a value of 2.33 was achieved. However, recent pharmacokinetic data compiled by Castiglioni et al. [15] evidenced that the formation of $\mathrm{BE}$, and consequently the $f$ value, may depend on the route of administration and on the preference of cocaine users in a given region. Thus, the $f$ value was refined to 3.59 considering pharmacokinetic data for COC intake, whether intranasal $(29.4 \%)$, intravenous $(37.4 \%)$, oral $(55 \%)$ or smoked $(14.8 \%)$. These data were also normalised considering epidemiological data on the cocaine consumption in Europe revealing a prevalence of $95 \%$ of intranasal cocaine users [42]. Thus, an 
excretion rate of $29.2 \%$ of $\mathrm{BE}$ in urine leads to the $f$ value of 3.59 [15]. Table 4 shows different $f$ values used in WBE studies.

In the Americas, cocaine is the second most common illicit drug consumed after cannabis [46]. Using the most recent pharmacokinetics data (previously described), Devault et al. [45] proposed a weighted urine excretion factor of $18.5 \%$ for the region of Martinique, a French territory in the Caribbean, where it is believed that crack is preferentially consumed (75\%). In Brazil, a report from the National Institute of Science and Technology for Policies on Alcohol and other Drugs [47] suggested the prevalence of intranasal adult users (70\%) in comparison with crack users (30\%) Thus, an excretion rate of $25.0 \%$ of $\mathrm{BE}$ in urine is obtained in accordance with the pharmacokinetic data compiled by Castiglioni et al. [15]. Consequently, a correction factor of 4.19 is more adequate in studies carried out in Brazil.

Figure 2 shows a day-to-day variation concerning cocaine use estimates for the two regions covered by the North-Wing and South-Wing WWTP. A per capita estimate is also portrayed for the Carnival Day at the northern region of Brasilia.

In both investigated areas, cocaine use was higher at the weekend, notably on Sunday, in comparison with the weekdays (Monday to Friday). In the region covered by the North-Wing WWTP, the average cocaine use during the weekdays $(2296 \pm 353 \mathrm{mg}$ day $^{-1} 1000$ inhab $\left.^{-1}\right)$ was $25 \%$ lower than the estimates for the weekend $(3100 \pm 233 \mathrm{mg}$ day $^{-1} 1000$ inhab $^{-1}$ ) and $36 \%$ lower than the estimates for Sunday $\left(3566 \pm 171 \mathrm{mg} \mathrm{day}^{-1}\right.$ 1000 inhab $\left.^{-1}\right)$. This result is similar to previous data produced in the same region in 2012, where cocaine use was 50\% higher in the weekend in comparison with weekdays [28]. In the region covered by the South-Wing WWTP, cocaine use on Sunday $\left(7385 \pm 121 \mathrm{mg} \mathrm{day}^{-1} 1000\right.$ inhab $\left.^{-1}\right)$ was more than three times higher than the average calculated for weekdays $\left(1707 \pm 250 \mathrm{mg} \mathrm{day}^{-1} 1000 \mathrm{inhab}^{-1}\right)$. In the Carnival Day, a 
cocaine consumption of $6229 \pm 219 \mathrm{mg} \mathrm{day}^{-1} 1000 \mathrm{inhab}^{-1}$ was depicted, being one of the highest reported in the literature, to the best of our knowledge.

So far, WBE results obtained in Brasilia over the past few years are the only ones produced in Brazil, a country with continental dimensions, with more than 200 million inhabitants, and with large urban areas, such as São Paulo and Rio de Janeiro, facing serious problems with drug trafficking and use $[48,49]$. Therefore, comparisons concerning drug use within the same economic and cultural context are still pending, but can be made in the future, as the WBE approach is expanded to other Brazilian cities. On the other hand, the data produced in the present work can be compared with those produced by Bijlsma et al. [9] in Colombia, a Latin American country neighbouring Brazil and one of the largest producers of cocaine in the world. In the cities of Bogotá and Medellín, average consumption on weekdays was $705 \pm 63$ and 2956 mg day ${ }^{-1} 1000$ inhab $^{-1}$, respectively, being similar to our results. However, differently from Brasilia and from most of the European cities, cocaine consumption during the weekend did not differ significantly $\left(835 \pm 51\right.$ and $3187 \pm 392 \mathrm{mg} \mathrm{day}^{-1} 1000$ inhab $^{-1}$ in Bogotá and Medellín, respectively) suggesting a constant use of the drug.

In Brasilia, cocaine consumption during the weekdays is higher in the northern region of Brasilia compared to the southern region. Although any hypothesis to explain this phenomenon is merely speculative, it is important to mention the main Campus of the University of Brasilia, as well as other universities, is located in the northern region. Together, they account for a university population of about 50,000 people. In addition, it has been reported that excessive drug use, including cocaine, is common in universities in Brazil [50]. Cocaine use in the region served by the North-Wing WWTP has been the highest in the Federal District since the first estimates were obtained [2830] probably as a result of this significant university population. 
The results shown in Figure 2 also point to an exceptionally high cocaine consumption on Sunday in the area served by the South-Wing WWTP. In this region, especially on the shores of Paranoá Lake, numerous nightclubs and bars concentrate most of the recreational and social activities of Brasilia, especially during the weekends. Thus, it is believed that the data may be influenced by some event of great proportions that may have occurred in the region. It is important to point out that both regions have bars, restaurants and other activities where drug use can happen on weekends. In the South Wing, however, are located the main establishments that can concentrate major festive events. This may be the reason why weekend consumption is about twice as high as the weekdays in the North-Wing and about five times higher in the South-Wing.

In order to explain the higher cocaine use during the weekends in both investigated regions, one can consider that this increase is a consequence of a number of festive events that typically occur during weekends in large cities. However, it is also important to consider a higher number of binge users, i.e., episodic users who were characterized by repeated administration of cocaine followed by a period of abstinence [51]. Thus, additional information is required to assess the users' profile using WBE data, such as the determination of behavioural biomarkers in the sewage. In this study, COE was used to investigate the co-consumption of alcohol and cocaine, but also as a preliminary tool to investigate the pattern of consumption by different types of users.

\subsection{Cocaine and Alcohol Co-consumption}

The amount of COE excreted in urine is less than $1 \%$ and highly dependent on the amount of alcohol and cocaine ingested [31,52]. For this reason, the COE/BE ratio was used to estimate the preferential consumption of cocaine alone or with alcohol [[27]]. In order to understand the co-consumption of drugs, Figure 3 shows COE/BE ratios 
obtained in the investigated samples.

In the literature, $\mathrm{COE} / \mathrm{BE}$ ratios in urine are very scarce, especially considering different routes of administration of cocaine [26,31,53]. Rodríguez-Álvarez et al. [27] investigated cocaine and alcohol consumption in two European cities using $\mathrm{COE}$ as an indicator of co-consumption and compiled pharmacological data concerning the simultaneous administration of both substances. The authors suggest a reference value of 0.039 for the $\mathrm{COE} / \mathrm{BE}$ ratio (shown in Figure 3), where higher values may indicate that cocaine is preferably consumed with alcohol.

In Figure 3, $\mathrm{COE} / \mathrm{BE}$ ratios calculated from wastewater analysis differ significantly between the two investigated regions. In the region covered by the NorthWing WWTP ratios higher than 0.039 were noticed in all days, except for the Sunday. As mentioned earlier, this behaviour may be also related to the higher student community in the northern region. In this region, the highest $\mathrm{COE} / \mathrm{BE}$ ratio was obtained for the sample collected on Saturday $(0.067 \pm 0.012)$. In the region covered by the South-Wing WWTP, the highest COE/BE ratio was also noticed on Saturday (0.037 \pm 0.006$)$, being similar to the cut-off value. During the weekdays, but also in the Sunday, ratios below the reference value as well as below the data obtained for the northern region were observed. COE/BE for the Carnival Holiday $(0.071 \pm 0.008)$ was the highest among the investigated samples.

It is important to notice that results for cocaine consumption in Figure 2, based on the use of BE in the back-calculation, indicates a higher drug use on Sundays. As the administration of alcohol decreases BE levels by approximately $48 \%$ in urine [31], the interpretation of our data may take into account that the co-consumption of alcohol and cocaine may also influence the day-to-day results portrayed in Figure 2, where higher cocaine use on Saturdays was probably underestimated. In the Carnival Day this 
behaviour was not evident probably due to the fact the alcohol consumption is high during the entire holiday and throughout the days of the festival. Thus, in this case, $\mathrm{COE} / \mathrm{BE}$, as well as data for cocaine consumption, were always high.

Another hypothesis to explain greater $\mathrm{COE} / \mathrm{BE}$ ratios on Saturdays rather than Sundays is based on the profile of users since different patterns of combined cocaine and alcohol use were reported by powder and crack users [54]. Guindalini et al. [55] show that powder and dual users (crack+powder) reported drinking more alcohol per week than crack cocaine users. Gossop et al. [56] found that the co-consumption of alcohol and cocaine is most common for powder (intranasal) users, while crack users may consume alcohol at the end of crack-using sessions. In addition, the authors show that during the administration of high episodic doses (binge), crack users drink lower amounts of alcohol than usual. Thus, considering that in Brazil there are at least $30 \%$ of crack cocaine users, peaks on the cocaine use estimates based on wastewater analyses may not be accompanied by the highest $\mathrm{COE} / \mathrm{BE}$ ratios determined in the samples, especially during typical day-to-day investigations. Finally, it is important to mention that more than $80 \%$ of the crack users that seeks treatment in Brasilia does not use crack at parties [57], corroborating our hypothesis.

All discussions made here to explain higher $\mathrm{COE} / \mathrm{BE}$ ratios on Saturdays rather than Sundays cannot be used for the sample collected in the Carnival Day, considering that a high pattern of consumption of different drugs is expected during the entire holiday. Finally, as pointed out by Rodríguez-Álvarez et al. [27], excretion data on COE are still scarce leading to possible biased speculations using COE/BE ratios. Of course, further pharmacokinetic studies are needed, especially considering different routes of administration of cocaine as well as different patterns of concomitant use in order to redefine this reference value and to improve the interpretation of WBE estimates. 


\subsection{Police seizures and WBE}

Drug seizure information was combined to WBE data in order to provide information concerning law enforcement and drug trafficking scenario. The Institute of Criminalistics of the Brazilian Technical Police provide data on cocaine seized, as well as the composition of drugs. Figure 4 shows the amount of crack and cocaine seized in different locations of the Brazilian Federal District, including Brasilia and its satellite cities, during the week investigated by the WBE approach.

A total of 104 seized samples were identified by routine procedures of the local Technical Police as hydrochloride cocaine (powder) or freebase cocaine (crack). Figure 4 shows that crack and cocaine (powder) are spread throughout the Brazilian Federal District. Approximately the same quantities of both drugs were seized during the week, i.e., $3.5 \mathrm{~kg}$ of crack rocks and $3.8 \mathrm{~kg}$ of powdered cocaine. Small quantities of crack were seized per police searches, since $90 \%$ of samples present masses below $11.4 \mathrm{~g}$. On the other hand, $90 \%$ of the cocaine powder samples present masses below $113.5 \mathrm{~g}$.

In Figure 5, the daily load of cocaine, estimated by WBE, is compared with the daily amount of crack and cocaine seized. For comparison purposes, the amount of cocaine consumed was extrapolated considering that the WBE data produced covers approximately $23 \%$ of the inhabitants [1].

Results shown in Figure 5 indicate a lack of correlation between crack + cocaine consumed and seized in the FD during the week investigated. This is probably due to the small amount of drug seized in comparison to that consumed. Findings of the Brazilian Federal Police chemical profiling program (PeQui project) showed that the purity of cocaine in 642 drugs samples obtained from seizures in the streets of five Brazilian states, including FD, was $49.8 \pm 29.5 \%$ [58]. Thus, it is possible to estimate that 
the effectiveness of routine police action during the week was able to prevent the circulation of about $3 \%$ of the drug demand.

Considering the purity of drugs trafficked on Brazilian streets, as well as the results regarding cocaine consumption in the Federal District obtained through WBE, it is possible to estimate that about $5.6 \pm 2.1$ tons of street-grade cocaine circulate in the FD per year. For the law enforcement point of view, information such as the number of drugs trafficked in a particular region, as well as the effectiveness of police seizures may support accurate actions to deal with drug trafficking and other public safety issues.

\section{Conclusion}

An analytical method based on SPE and LC-QTOF was used to quantify COC and two metabolites, $\mathrm{BE}$ and $\mathrm{COE}$, in wastewater samples collected in the Brazilian Capital. A day-to-day analysis revealed higher cocaine use on Sunday in the areas covered by two wastewater treatment plants (South-Wing and North-Wing WWTP). In the northern region, cocaine use was higher in comparison with the southern region on weekdays. In these days, $\mathrm{COE} / \mathrm{BE}$ ratios were also higher in the northern region indicating the coconsumption of alcohol and cocaine. As cocaine use was higher on Sunday, it was expected a high COE/BE during this day. However, ratios were higher on Saturdays rather than Sundays. This behaviour may be explained by the decrease of BE excretion during the co-consumption of cocaine with alcohol, leading to an underestimation of the cocaine use estimates on Saturdays. In addition, as the Brazilian community experiences a significant use of smoked freebase cocaine, in the form of crack, the patterns of drug use may also contribute to add some bias to the results. Crack users usually drink lower amounts of alcohol, at the end of drug-using sessions and isolated from social or festive 
events. Thus, peaks of cocaine consumption may not be accompanied by high COE/BE values. In the Carnival Day sample, investigated by LC-QqQ, a high cocaine use was accompanied by the highest $\mathrm{COE} / \mathrm{BE}$ ratio, probably due to the fact that drug and alcohol use is high and steady throughout the entire holiday week. Data collected by the Brazilian Civil Policed during the study period revealed that about $3 \%$ of the crack + cocaine circulating in the streets of the Brazilian Capital were seized. Finally, considering the purity of drugs trafficked in Brazil, it is estimated that about $5.6 \pm 2.1$ tons of crack+cocaine circulate annually in the Brazilian Federal District.

\section{Acknowledgements}

This work was supported by the Federal District Research Foundation under Grant 193.000.916/2015; the Spanish Ministry of Economy and Competitiveness under Grant CTM2017-84763-C3-2-R; the Galician Council of Culture, Education and Universities under Grants ED431C2017/36 and IGM postdoctoral contract, Plan Galego I2CModalidade B, ED481D 2017/003; and FEDER/ERDF.

\section{References}

[1] Brazilian Institute of Geography and Statistics, Population Estimates. <ftp://ftp.ibge.gov.br/Estimativas_de_Populacao/Estimativas_2018/estimativa_d ou_2018.pdf $>$.

[2] M.I.C. Gandolfo, H.H. Cardona, J.T. Assis, R.R. Mohr, M.F.O. Sudbrack, and C. Strike, Psicol. Teor. Pesqui. 32, 1 (2010).

[3] L. Toledo, A. Gongora, and F. Bastos, Cien. Saude Colet. 22, 31 (2017). doi:10.1590/1413-81232017221.02852016. 
[4] E. Gracia-Lor, S. Castiglioni, R. Bade, F. Been, E. Castrignano, A. Covaci, I. Gonzalez-Marino, E. Hapeshi, B. Kasprzyk-Hordern, J. Kinyua, F.Y. Lai, T. Letzel, L. Lopardo, M.R. Meyer, J. O’Brien, P. Ramin, N.I. Rousis, A. Rydevik, Y. Ryu, M.M. Santos, I. Senta, N.S. Thomaidis, S. Veloutsou, Z.G. Yang, E. Zuccato, and L. Bijlsma, Environ. Int. 99, 131 (2017). doi:10.1016/j.envint.2016.12.016.

[5] D.A. Devault, H. Maguet, S. Merle, A. Péné-Annette, and Y. Lévi, Environ. Sci. Pollut. Res. 25, 27819 (2018). doi:10.1007/s11356-018-2864-7.

[6] S. Castiglioni, R. Bagnati, M. Melis, D. Panawennage, P. Chiarelli, R. Fanelli, and E. Zuccato, Water Res. 45, 5141 (2011). doi:10.1016/j.watres.2011.07.017.

[7] K.V Thomas, L. Bijlsma, S. Castiglioni, A. Covaci, E. Emke, R. Grabic, F. Hernández, S. Karolak, B. Kasprzyk-Hordern, R.H. Lindberg, M.L. de Alda, A. Meierjohann, C. Ort, Y. Pico, J.B. Quintana, M. Reid, J. Rieckermann, S. Terzic, A.L.N. van Nuijs, and P. de Voogt, Sci. Total Environ. 432, 432 (2012). doi:10.1016/j.scitotenv.2012.06.069.

[8] F.Y. Lai, J. O’Brien, R. Bruno, W. Hall, J. Prichard, P. Kirkbride, C. Gartner, P. Thai, S. Carter, B. Lloyd, L. Burns, and J. Mueller, Sci. Total Environ. 568, 810 (2016). doi:10.1016/j.scitotenv.2016.05.207.

[9] L. Bijlsma, A.M. Botero-Coy, R.J. Rincón, G.A. Peñuela, and F. Hernández, Sci. Total Environ. 565, 984 (2016). doi:10.1016/j.scitotenv.2016.05.078.

[10] N. Mastroianni, E. López-García, C. Postigo, D. Barceló, and M.L. de Alda, Sci. Total Environ. 609, 916 (2017). doi:10.1016/j.scitotenv.2017.07.126. 
[11] H.T. Nguyen, P.K. Thai, S.L. Kaserzon, J.W. O’Brien, G. Eaglesham, and J.F. Mueller, Sci. Total Environ. 631-632, 469 (2018).

doi:10.1016/j.scitotenv.2018.02.309.

[12] K.S. Foppe, D.R. Hammond-Weinberger, and B. Subedi, Sci. Total Environ. 633, 249 (2018). doi:10.1016/j.scitotenv.2018.03.175.

[13] J. Prichard, W. Hall, P. de Voogt, and E. Zuccato, Sci. Total Environ. 472, 550 (2014). doi:10.1016/j.scitotenv.2013.11.039.

[14] W. Hall, J. Prichard, P. Kirkbride, R. Bruno, P.K. Thai, C. Gartner, F.Y. Lai, C. Ort, and J.F. Mueller, Addiction. 107, 1767 (2012). doi:10.1111/j.13600443.2012.03887.x.

[15] S. Castiglioni, L. Bijlsma, A. Covaci, E. Emke, F. Hernández, M. Reid, C. Ort, K.V. Thomas, A.L.N. Van Nuijs, P. De Voogt, and E. Zuccato, Env. Sci Technol. 47, 1452 (2013). doi:10.1021/es302722f.

[16] A.L.N. van Nuijs, B. Pecceu, L. Theunis, N. Dubois, C. Charlier, P.G. Jorens, L. Bervoets, R. Blust, H. Meulemans, H. Neels, and A. Covaci, Addiction. 104, 734 (2009). doi:10.1111/j.1360-0443.2009.02523.x.

[17] L.B. Duailibi, M. Ribeiro, and R. Laranjeira, Cad. Saude Publica. 24, s545 (2008). doi:10.1590/S0102-311X2008001600007.

[18] E. Zuccato, C. Chiabrando, S. Castiglioni, R. Bagnati, and R. Fanelli, Environ. Health Perspect. 116, 1027 (2008). doi:10.1289/ehp.11022.

[19] M. Ribeiro and R.O. Laranjeira, O Tratamento do Usuário de Crack, 2nd ed. (Artmed, Porto Alegre, 2012). 
[20] National Institute on Drug Abuse, Advancing Addiction Science, Drug Facts, Cocaine $<$ https://www.drugabuse.gov/publications/drugfacts/cocaine $>$.

[21] A.S. Fandiño, S.W. Toennes, and G.F. Kauert, J. Anal. Toxicol. 26, 567 (2002). doi:10.1093/jat/26.8.567.

[22] M. Escobar, J.N. Scherer, C.M. Soares, L.S.P. Guimaraes, M.E. Hagen, L. von Diemen, and F. Pechansky, Rev. Bras. Psiquiatr. 40, 354 (2018). doi:10.1590/1516-4446-2017-2409.

[23] S. Santos, M.T. Brugal, G. Barrio, Y. Castellano, A. Domingo-Salvany, A. Espelt, M.J. Bravo, L. De La Fuente, F. Fernández, F. González, D. Lacasa, M. Ambros, E. Mejías, G. Molist, M. Neira, J. Pulido, F. Sánchez, T. Silva, F. Vallejo, R. Ballesta, and B. Vázquez, Drug Alcohol Rev. 31, 439 (2012). doi:10.1111/j.1465-3362.2011.00411.x.

[24] L.D. Wilson and S. French, J Toxicol Clin Toxicol 40, 535 (2002). doi:10.1081/CLT-120014642.

[25] A.M. Bermejo, P. López, I. Álvarez, M.J. Tabernero, and P. Fernández, Forensic Sci. Int. 156, 2 (2006). doi:10.1016/j.forsciint.2005.09.007.

[26] B. Occupati, A. Rotulo, F. Gori, F. Gambassi, E. Bertol, and E. Masini, Clin. Toxicol. 55, 445 (2017). doi:10.1080/15563650.2017.1309792.

[27] T. Rodríguez-Álvarez, I. Racamonde, I. González-Mariño, A. Borsotti, R. Rodil, I. Rodríguez, E. Zuccato, J.B. Quintana, and S. Castiglioni, Sci. Total Environ. 536, 91 (2015). doi:10.1016/j.scitotenv.2015.07.016.

[28] F.F. Sodré, R.S. Feitosa, W.F. Jardim, and A.O. Maldaner, J. Braz. Chem. Soc. 
29, 2287 (2018). doi:10.21577/0103-5053.20180105.

[29] F.F. Sodré, G.B. Souza, R.S. Feitosa, C.E.B. Pereira, and A.O. Maldaner, J. Braz. Chem. Soc. 28, 2146 (2017). doi:10.21577/0103-5053.20170063.

[30] A.O. Maldaner, L.L. Schmidt, M.A.F. Locatelli, W.F. Jardim, F.F. Sodré, F. V Almeida, C.E.B. Pereira, and C.M. Silva, J. Braz. Chem. Soc. 23, 861 (2012). doi:10.1590/S0103-50532012000500011.

[31] D.S. Harris, E.T. Everhart, J. Mendelson, and R.T. Jones, Drug Alcohol Depend. 72, 169 (2003). doi:10.1016/S0376-8716(03)00200-X.

[32] M. Gorgulho and V. Da Ros, Int. J. Drug Policy 17, 350 (2006). doi:10.1016/j.drugpo.2006.05.003.

[33] B.K. Matuszewski, M.L. Constanzer, and C.M. Chavez-Eng, Anal. Chem. 75, 3019 (2003). doi:10.1021/ac020361s.

[34] A.-K. McCall, R. Bade, J. Kinyua, F.Y. Lai, P.K. Thai, A. Covaci, L. Bijlsma, A.L.N. van Nuijs, and C. Ort, Water Res. 88, 933 (2016). doi:10.1016/j.watres.2015.10.040.

[35] A.L.N. van Nuijs, K. Abdellati, L. Bervoets, R. Blust, P.G. Jorens, H. Neels, and A. Covaci, J. Hazard. Mater. 239, 19 (2012). doi:10.1016/j.jhazmat.2012.04.030.

[36] D.R. Baker, L. Barron, and B. Kasprzyk-Hordern, Sci. Total Environ. 487, 629 (2014). doi:10.1016/j.scitotenv.2013.11.107.

[37] P.K. Thai, G. Jiang, W. Gernjak, Z. Yuan, F.Y. Lai, and J.F. Mueller, Water Res. 48, 538 (2014). doi:10.1016/j.watres.2013.10.019. 
[38] D.A. Devault, Y. Lévi, and S. Karolak, Sci. Total Environ. 584-585, 252 (2017). doi: 10.1016/j.scitotenv.2017.01.114.

[39] M. Melis, S. Castiglioni, and E. Zuccato, in Illicit Drugs Environ. Occur. Anal. Fate Using Mass Spectrom., edited by S. Castiglioni, E. Zuccato, and R. Fanelli (John Wiley \& Sons, Inc., 2011), pp. 29-52.

[40] E. Gracia-Lor, E. Zuccato, and S. Castiglioni, Sci. Total Environ. 573, 1648 (2016). doi:10.1016/j.scitotenv.2016.09.179.

[41] E. Zuccato, C. Chiabrando, S. Castiglioni, D. Calamari, R. Bagnati, S. Schiarea, and R. Fanelli, Environ. Health 4, 14 (2005). doi:10.1186/1476-069X-4-14.

[42] M. Prinzleve, C. Haasen, H. Zurhold, J.L. Matali, E. Bruguera, J. Gerevich, E. Bácskai, N. Ryder, S. Butler, V. Manning, M. Gossop, A.M. Pezous, A. Verster, A. Camposeragna, P. Andersson, B. Olsson, A. Primorac, G. Fischer, F. Güttinger, J. Rehm, and M. Krausz, Eur. Addict. Res. 10, 147 (2004). doi: $10.1159 / 000079835$.

[43] A.L.N. van Nuijs, J.-F. Mougel, I. Tarcomnicu, L. Bervoets, R. Blust, P.G. Jorens, H. Neels, and A. Covaci, Environ. Int. 37, 612 (2011). doi:10.1016/j.envint.2010.12.006.

[44] S. Castiglioni, editor, Assessing Illicit Drugs in Wastewater: Advances in Wastewater-Based Drug Epidemiology, EMCDDA Insights 22 (Publications Office of the European Union, Luxembourg, 2016).

[45] D.A. Devault, T. Néfau, H. Pascaline, S. Karolak, Y. Levi, D.A. Damien, N. Thomas, P. Helene, K. Sara, and L. Yves, Sci. Total Environ. 490, 970 (2014). 
doi:10.1016/j.scitotenv.2014.05.090.

[46] B. Fischer, P. Blanken, D. Da Silveira, A. Gallassi, E.M. Goldner, J. Rehm, M. Tyndall, and E. Wood, Int. J. Drug Policy 26, 352 (2015).

doi:10.1016/j.drugpo.2015.01.002.

[47] R. Laranjeira, editor, Segundo Levantamento Nacional de Álcool e Drogas (UNIFESP, São Paulo, 2013).

[48] Human Rights Watch, Lethal Force: Police Violence and Public Security in Rio de Janeiro and São Paulo, <http://www.hrw.org/node/87020>.

[49] L. Toledo, I. Cano, L. Bastos, N. Bertoni, and F.I. Bastos, Int. J. Drug Policy. 49, 65 (2017). doi:10.1016/j.drugpo.2017.07.034.

[50] J.E. Fiorini, A.L. Alves, L.R. Ferreira, C.M. Fiorini, S.W. Durães, R.L.D. Santos, L.C. do Nascimento, A.M.V. Geraldini, and C. de F. Ortiz, Rev. Hosp. Clin. Fac. Med. Sao. Paulo. 58, 199 (2003). doi:10.1590/S0041-87812003000400003.

[51] S.K. Vosburg, M. Haney, E. Rubin, and R.W. Foltin, Drug Alcohol Depend 110, 144 (2010). doi:10.1016/j.drugalcdep.2010.02.015.

[52] J. Cami, M. Farré, M.L. González, J. Segura, and R. de la Torre, in The Consequences of Alcoholism: Medical, Neuropsychiatric, Economic, CrossCultural, edited by M. Galanter (Springer US, Boston, 1998).

[53] E.D. Herbst, D.S. Harris, E.T. Everhart, J. Mendelson, P. Jacob, and R.T. Jones, Exp. Clin. Psychopharmacol. 19, 95 (2011). doi:10.1037/a0022950.

[54] M. Gossop, V. Manning, and G. Ridge, Alcohol Alcohol. 41, 121 (2006). 
doi:10.1093/alcalc/agh260.

[55] C. Guindalini, H. Vallada, G. Breen, and R. Laranjeira, BMC Public Health. 6, 1 (2006). doi:10.1186/1471-2458-6-10.

[56] M. Gossop, V. Manning, and G. Ridge, Addiction 101, 1292 (2006). doi:10.1111/j.1360-0443.2006.01497.x.

[57] M.I.G. Conceição, H.H. Cardona, J.T. Assis, R.R. Mohr, M.F.O. Sudbrack, and C. Strike, Psicol. Teor. E Pesqui. 32, 1 (2016). doi:10.1590/0102-3772e32ne216.

[58] A.O. Maldaner, E.D. Botelho, J.J. Zacca, R.C.A. Melo, J.L. Costa, I. Zancanaro, C.S.L. Oliveira, L.B. Kasakoff, and T.R.L.C. Paixao, J. Braz. Chem. Soc. 27, 719 (2016). doi:10.5935/0103-5053.20150321. 
Table 1. Retention times and QTOF $m / z$ values used for the determination of the investigated analytes.

\begin{tabular}{llll}
\hline Analyte & Retention time $(\mathrm{min})$ & Precursor ion $(\mathrm{m} / \mathrm{z})$ & Product ions $(\mathrm{m} / \mathrm{z})$ \\
\hline COC & 7.7 & 304.1543 & 182.1176 \\
& & & 82.0651 \\
$\mathrm{BE}$ & 7.5 & 290.1387 & 168.1019 \\
& & & 105.0335 \\
$\mathrm{COE}$ & 7.9 & 318.1700 & 196.1322 \\
& & & 150.0913 \\
$\mathrm{COC}-\mathrm{d}_{3}$ & 7.7 & 307.1732 & 185.1364 \\
$\mathrm{BE}-\mathrm{d}_{3}$ & 7.5 & 293.1575 & 171.1207 \\
COE- $_{3}$ & 7.9 & 321.1888 & 199.1520 \\
\hline
\end{tabular}


Table 2. Comparison between wastewater stability tests for COC, BE and COE

\begin{tabular}{|c|c|c|c|c|}
\hline \multirow[t]{2}{*}{ Experimental conditions } & \multicolumn{3}{|c|}{ Percentage of variation (\%) } & \multirow[t]{2}{*}{ Reference } \\
\hline & $\mathrm{COC}$ & $\mathrm{BE}$ & $\mathrm{COE}$ & \\
\hline $12 \mathrm{~h}, 20^{\circ} \mathrm{C}, \mathrm{pH} 7.5$ & -40 & +6 & - & [35] \\
\hline $12 \mathrm{~h}, 19^{\circ} \mathrm{C}, \mathrm{pH} 7.4$ & -7.7 & +5.5 & -6.8 & [36] \\
\hline $24 \mathrm{~h}, 19^{\circ} \mathrm{C}, \mathrm{pH} 7.4$ & -12.3 & +7.4 & - & [36] \\
\hline $12 \mathrm{~h}, 20^{\circ} \mathrm{C}, \mathrm{pH} 7.5$ & -20 & +28 & - & [37] \\
\hline $72 \mathrm{~h}, 24^{\circ} \mathrm{C}, \mathrm{pH} 7.5$ & -29.4 & +11.3 & - & [28] \\
\hline $24 \mathrm{~h}, 20^{\circ} \mathrm{C}, \mathrm{pH} 7.6$ & -80 & +20 & - & [38] \\
\hline $24 \mathrm{~h}, 20^{\circ} \mathrm{C}, \mathrm{pH} 6.5$ & -80 & +25 & - & [38] \\
\hline $24 \mathrm{~h}, 20^{\circ} \mathrm{C}, \mathrm{pH} 5$ & $<-15 \%$ & 0 & - & [38] \\
\hline $24 \mathrm{~h}, 30^{\circ} \mathrm{C}, \mathrm{pH} 7.6$ & -80 & +20 & - & [38] \\
\hline $24 \mathrm{~h}, 30^{\circ} \mathrm{C}, \mathrm{pH} 6.5$ & -80 & +25 & - & [38] \\
\hline $24 \mathrm{~h}, 30^{\circ} \mathrm{C}, \mathrm{pH} 5$ & $<-15 \%$ & 0 & - & [38] \\
\hline $24 \mathrm{~h}, 23^{\circ} \mathrm{C}, \mathrm{pH} 7.5$ & $-14.6 \pm 1.6$ & $+9.0 \pm 4.0$ & $-2.0 \pm 0.2$ & This work \\
\hline
\end{tabular}


Table 4. Correction factors $(f)$ used in WBE studies considering different regions, routes of administration and prevalence of drug users.

\begin{tabular}{|c|c|c|c|c|c|c|c|}
\hline \multirow[t]{2}{*}{ Region } & \multicolumn{4}{|c|}{ Route of Administration (\%) } & \multirow{2}{*}{$\begin{array}{l}\text { Excretion } \\
\text { Factor (\%) }\end{array}$} & \multirow{2}{*}{$\begin{array}{l}\text { Correction } \\
\text { Factor } f\end{array}$} & \multirow[t]{2}{*}{ Reference } \\
\hline & Intranasal & Smoked & Injected & Oral & & & \\
\hline World & 100 & - & - & - & 45.0 & 2.33 & [43] \\
\hline World & 100 & - & - & - & 35.0 & 3.00 & [44] \\
\hline Europe & 95 & 4 & 2 & - & 29.2 & 3.59 & {$[15]$} \\
\hline Martinique & 25 & 75 & - & - & 18.5 & 5.67 & {$[45]$} \\
\hline Brazil & 70 & 30 & - & - & 25.0 & 4.19 & [28] \\
\hline
\end{tabular}


Table 3. Concentration (average \pm standard deviation) of COC, BE and COE $\left(\mathrm{ng} \mathrm{L}^{-1}\right)$ in sewage samples $(n=3)$ collected in two WWTP of the Brazilian Capital within a week period.

\begin{tabular}{|c|c|c|c|c|c|c|}
\hline \multirow[t]{2}{*}{ Date } & \multicolumn{2}{|l|}{$\mathrm{COC}$} & \multicolumn{2}{|l|}{$\mathrm{BE}$} & \multicolumn{2}{|l|}{$\mathrm{COE}$} \\
\hline & S-W & $\mathrm{N}-\mathrm{W}$ & S-W & $\mathrm{N}-\mathrm{W}$ & S-W & $\mathrm{N}-\mathrm{W}$ \\
\hline Tue (30.5.17) & $944 \pm 77$ & NA & $2115 \pm 162$ & NA & $<14^{\mathrm{a}}$ & NA \\
\hline Wed (31.5.17) & $787 \pm 50$ & $865 \pm 63$ & $2000 \pm 150$ & $1598 \pm 127$ & $<14^{\mathrm{a}}$ & $59 \pm 13$ \\
\hline Thu (1.6.17) & $1175 \pm 125$ & $835 \pm 58$ & $2374 \pm 94$ & $1746 \pm 150$ & $<14^{\mathrm{a}}$ & $78 \pm 15$ \\
\hline Fri (2.6.17) & $635 \pm 79$ & NA & $1659 \pm 146$ & NA & $<14^{\mathrm{a}}$ & NA \\
\hline Sat (3.6.17) & $977 \pm 73$ & $1376 \pm 111$ & $2745 \pm 152$ & $2788 \pm 168$ & $101 \pm 16$ & $188 \pm 34$ \\
\hline Sun (4.6.17) & $1983 \pm 40$ & $1502 \pm 144$ & $8559 \pm 141$ & $4155 \pm 199$ & $155 \pm 14$ & $104 \pm 29$ \\
\hline Mon (5.6.17) & $743 \pm 51$ & $1256 \pm 70$ & $1636 \pm 93$ & $2338 \pm 148$ & $<42^{\mathrm{b}}$ & $103 \pm 28$ \\
\hline Tue (6.6.17) & $837 \pm 47$ & $1066 \pm 130$ & $1599 \pm 106$ & $1866 \pm 151$ & $<42^{\mathrm{b}}$ & $89 \pm 19$ \\
\hline Tue (13.2.18) & NA & $1153 \pm 143$ & NA & $5920 \pm 208$ & NA & $422 \pm 44$ \\
\hline
\end{tabular}

${ }^{\mathrm{a}}$ concentrations below LOD

${ }^{b}$ concentrations between LOD and LOQ

S-W: South-Wing WWTP, N-W: North-Wing WWTP, NA: Not Analysed 
Figure Captions

Figure 1. Areas served by the two main WWTPs of Brasilia in the FD. Red and blue pins are the location of North-Wing and South-Wing WWTPs, respectively, on the banks of Paranoá Lake.

Figure 2. Day-to-day profile of cocaine use assessed by wastewater-based epidemiology in areas served by two WWTP of Brazilian Capital.

Figure 3. Variation of $\mathrm{COE} / \mathrm{BE}$ ratios in sewage samples collected during a week period in two WWTPs of the Brazilian capital. The dotted line represents the threshold value of 0.039 suggesting a preferably cocaine consumption with alcohol [27].

Figure 4. Distribution of crack and cocaine (powder), in grams, seized in Brasilia and satellite cities by the Brazilian Civil Police from 30th May to 6th June 2017.

Figure 5. Seizure of crack and cocaine in relation to the load found by wastewater-based epidemiology. 


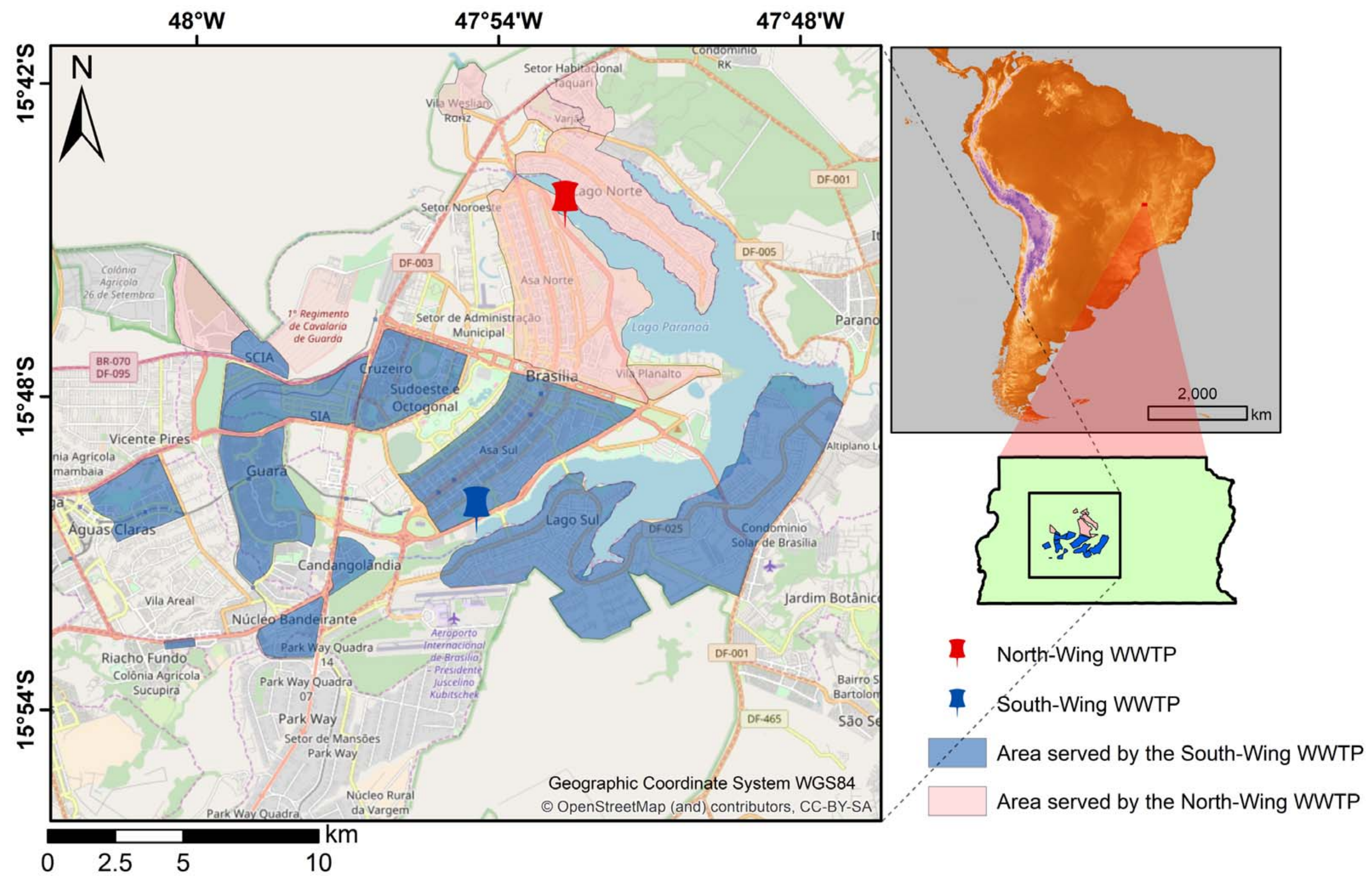




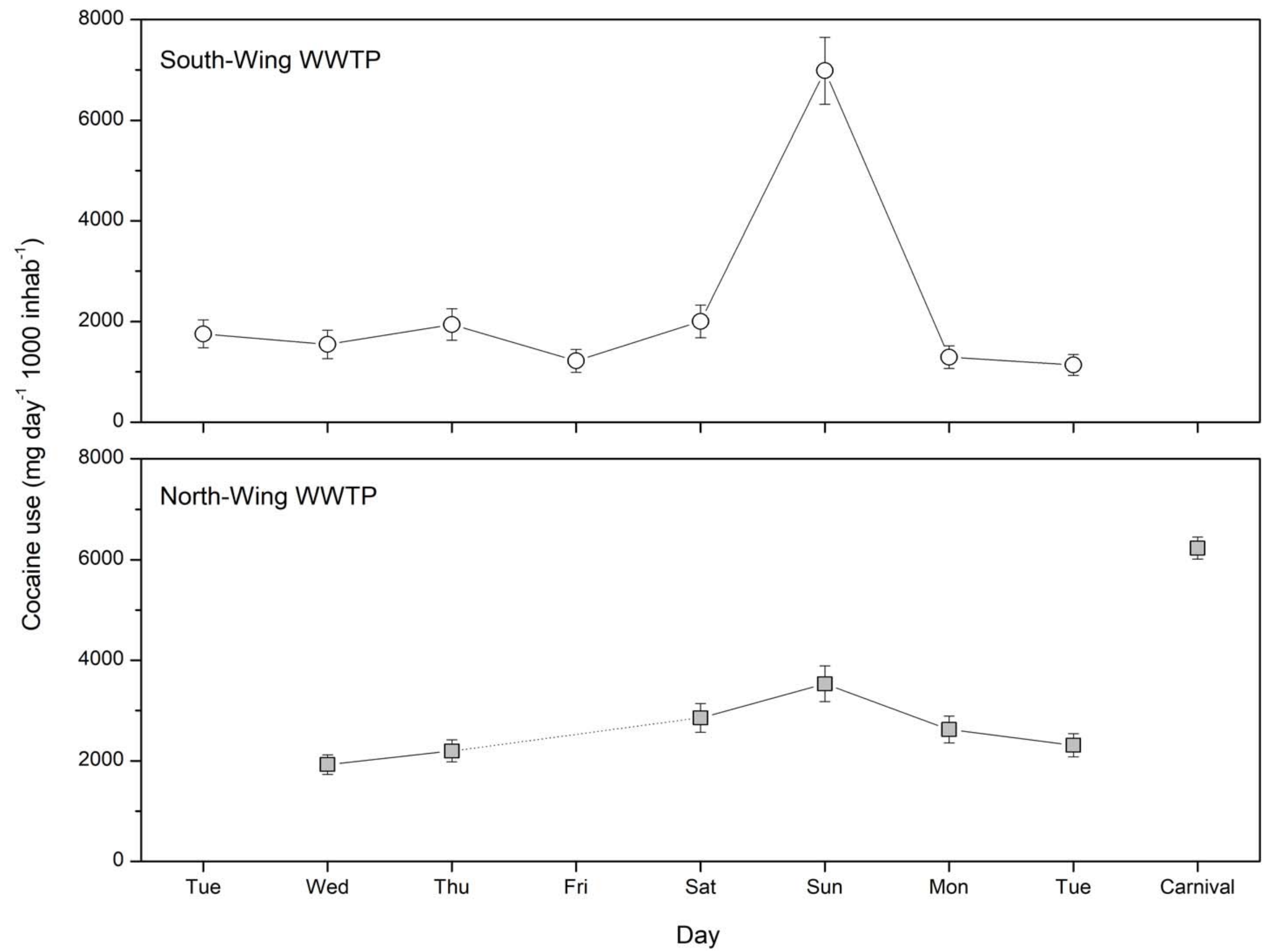




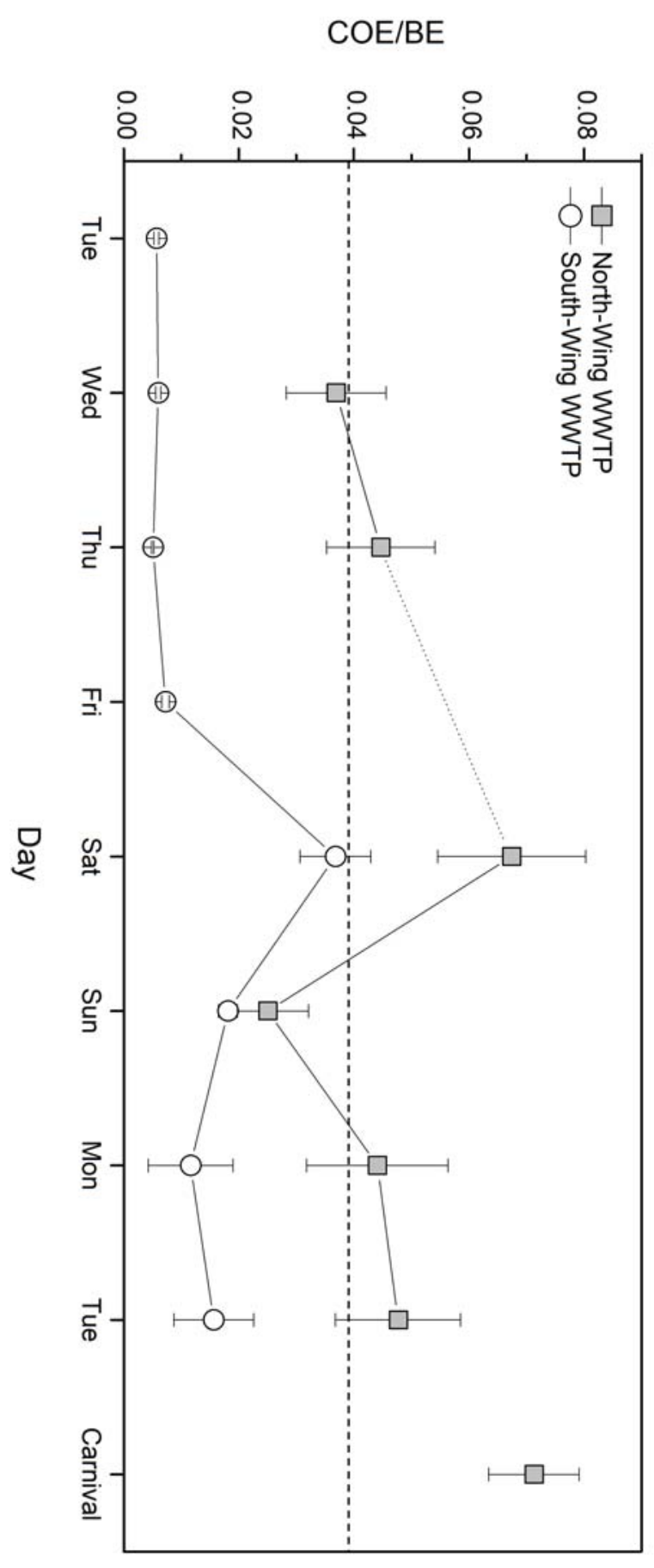




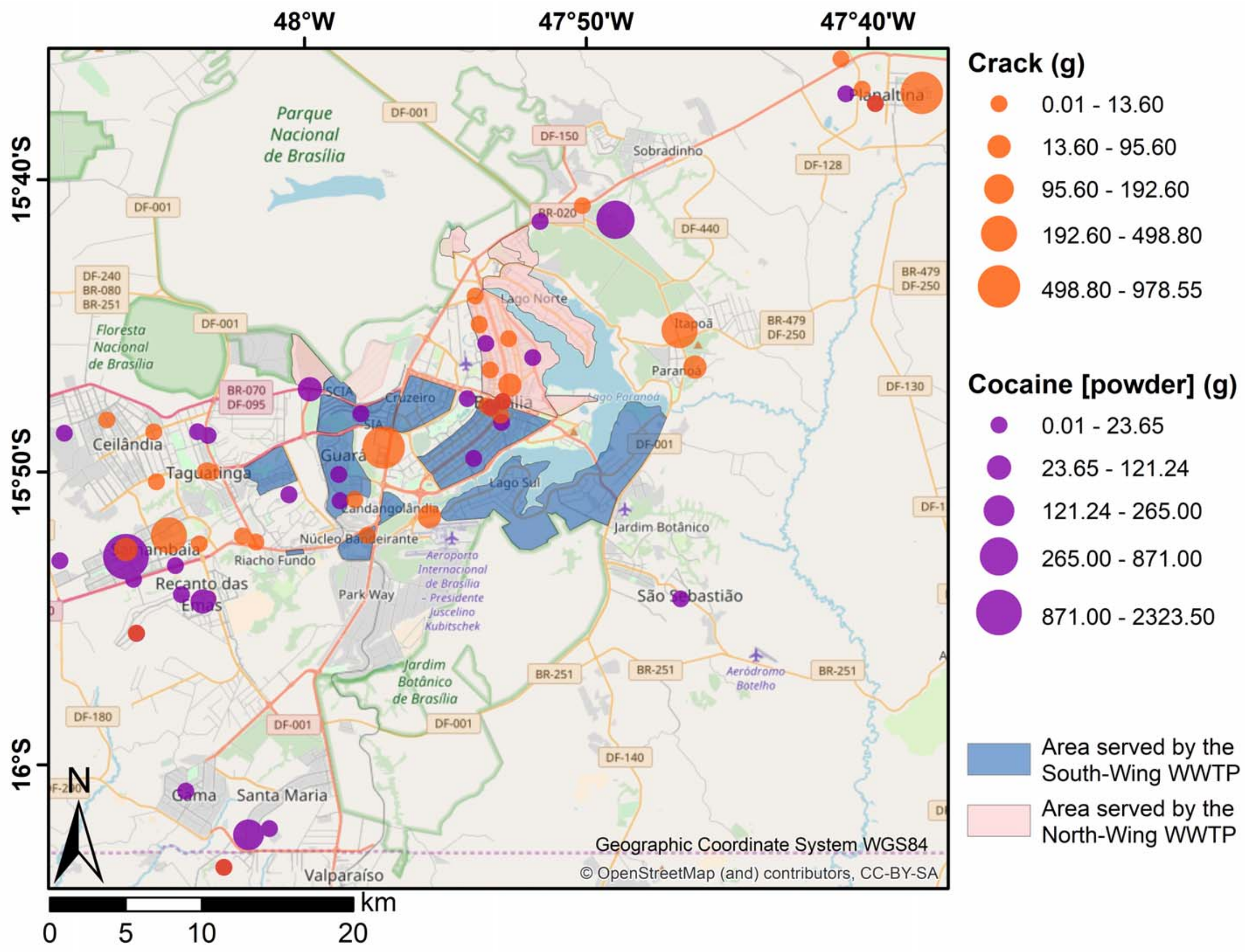




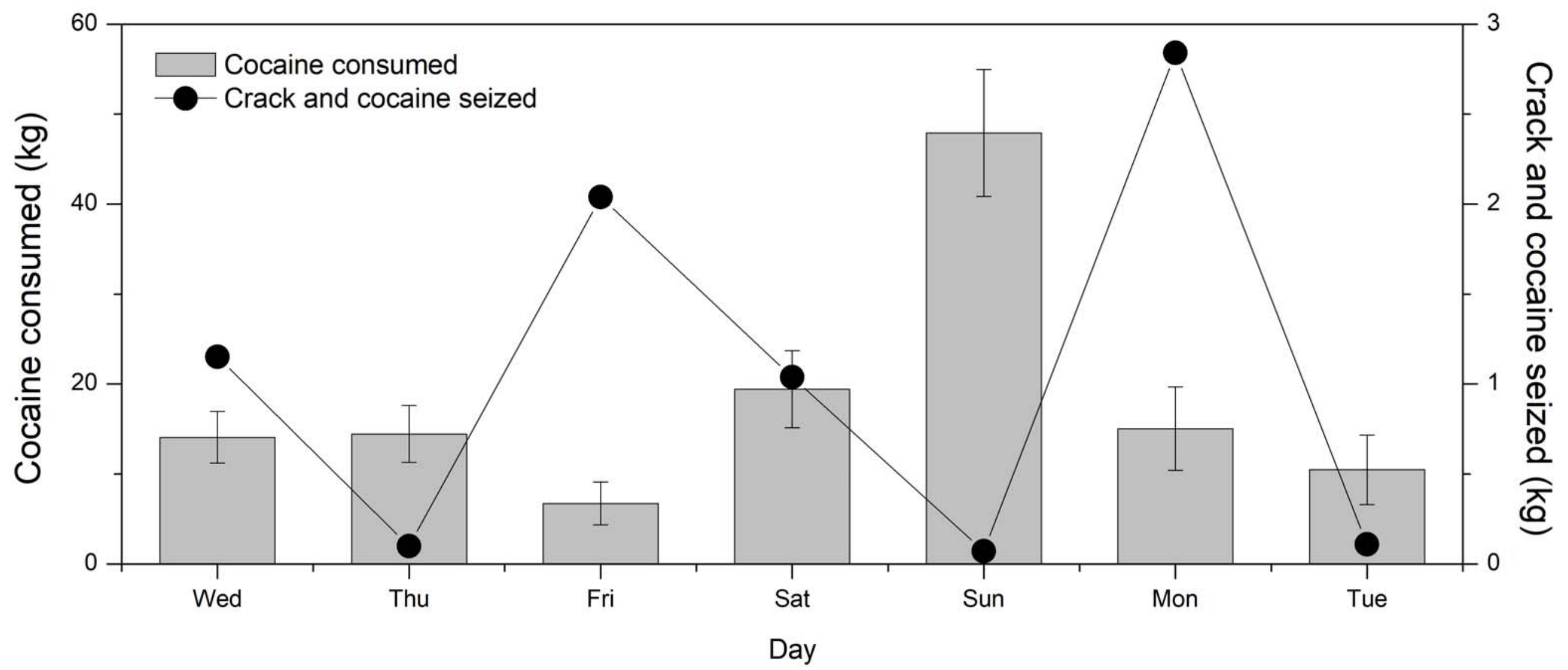




\section{Assessing Cocaine Use Patterns in the Brazilian Capital by Wastewater-Based Epidemiology}

K. M. Silva ${ }^{\mathrm{a}}$, J. B. Quintana ${ }^{\mathrm{b}}$, I. Gonzalez-Mariño ${ }^{\mathrm{b}}$, R. Rodil ${ }^{\mathrm{b}}$, A. D.

Gallassi $^{\mathrm{c}}$, L. C. Arantes ${ }^{\mathrm{d}}$ and F. F. Sodré ${ }^{\mathrm{a} *}$

${ }^{a}$ Institute of Chemistry, University of Brasilia, Brasilia, 70297-400, Brazil; ${ }^{b}$ University

of Santiago de Compostela, Santiago de Compostela, 15782, Spain; ${ }^{c}$ Center of Drugs

and Associated Vulnerabilities, University of Brasilia, Ceilândia campus, 72220-900,

Brazil; ${ }^{d}$ Institute of Criminalistics, Department of Technical Police, Brasília, 70610-

907, Brazil

*ffsodre@unb.br

\section{SUPPLEMENTAL MATERIAL}

\section{Linearity and Limits of Detection and Quantification}

Linear regression parameters of the analytical curves constructed for quantification of cocaine (COC), benzoylecgonine (BE) and cocaethylene (COE) in wastewater samples by liquid chromatography coupled to high-resolution hybrid quadrupole-time-of-flight mass spectrometry (LC-QTOF) are presented in Table S1.

Table S1. Parameters of the analytical curves and limits of determination and quantification for the investigated analytes determined by LC-QTOF.

\begin{tabular}{lllllllll}
\hline Analyte & IS & $\begin{array}{l}\text { Working } \\
\text { Range }\end{array}$ & Analytical Curve & $\mathrm{R}^{2}$ & LODi & LOQ $i$ & LODm* ${ }^{*}$ LOQ $m^{*}$ \\
\hline & & $\mu g L^{-1}$ & $y=\mathrm{a}+\mathrm{b} x$ & & $\mu g L^{-1}$ & $\mu g L^{-1}$ & $n g L^{-1}$ & $n g L^{-1}$ \\
COC & COC-d3 & $90-700$ & $y=0.045+0.005 x$ & 0.996 & 27 & 90 & 86 & 288 \\
BE & BE-d3 & $70-1000$ & $y=-0.046+0.007 x$ & 0.999 & 21 & 70 & 65 & 215 \\
COE & COE-d3 & $15-100$ & $y=0.005+0.051 x$ & 0.991 & 5 & 15 & 14 & 42 \\
\hline
\end{tabular}

COC: cocaine, BE: benzoylecgonine, COE: cocaethylene, IS: internal standard, a: linear coefficient, b: angular coefficient, LODi: limit of detection of the instrument, LOQi: limit of quantification of the instrument, LODm: method limit of detection, LOQm: method limit of quantification. * Limits calculated considering the efficiency of the method $(E f)$ and a concentration factor of 250 . 
Analytical curves using internal standards were homoscedastic. Instrumental limits of quantification (LOQi) were expressed by the lower standard concentration of the analytical curves, while instrumental limits of detection (LODi) were calculated using LOQ $i$ divided by the factor of 3.3. Limits of detection and quantification of the method, LODm, and LOQm, respectively, were obtained using LODi and LOQ $i$ multiplied by the efficiency of the method $(E f)$ and divided by the pre-concentration factor of 250 .

\section{Analytes Quantification in Brazil}

The Carnival Day sample, as well as the samples from the stability test, were analyzed in Brazil using liquid chromatograph (Agilent 1200 Series) coupled to triple-quadrupole (QqQ) mass spectrometer (QTRAP 3200, Sciex) with electrospray ionization (ESI) interface operating at $550{ }^{\circ} \mathrm{C}$ and $4500 \mathrm{~V}$, using nitrogen as curtain gas at $15 \mathrm{psi}$ and as auxiliary nebulizing gas (GS1 and GS2) at 45 psi.

Separation was performed using an Eclipse XDB-C18 column $(4,6 \times 150 \mathrm{~mm}$,

particle size of $5 \mu \mathrm{m}$, Agilent) with gradient elution $\left(0.3 \mathrm{~mL} \mathrm{~min}^{-1}\right)$ water and in methanol as mobile phases containing $0.1 \%(\mathrm{v} / \mathrm{v})$ of formic acid. The gradient was achieved by maintaining for 4 min a relative methanol concentration of $10 \%$, followed by the increase to $100 \%$ in $6 \mathrm{~min}$, and held constant for another $1 \mathrm{~min}$. After readjusting to the initial conditions, the system was re-equilibrated for $7 \mathrm{~min}$. The injection volume was $2.0 \mu \mathrm{L}$.

Mass spectrometric analyses were carried out using the multiple reaction monitoring (MRM) mode in order to identify and quantify the target analytes by measuring the fragmentation products of each protonated molecular ions $[\mathrm{M}+\mathrm{H}]^{+}$. Table S2 shows the MRM transitions used alongside with other instrumental parameters. 
Table S2. LC-MS/MS parameters used during the analysis

\begin{tabular}{lllllll}
\hline Analyte & DP $(\mathrm{V})$ & EP $(\mathrm{V})$ & CEP $(\mathrm{V})$ & $\begin{array}{l}\text { MRM transitions } \\
(\mathrm{m} / \mathrm{z})\end{array}$ & CE $(\mathrm{V})$ & CXP $(\mathrm{V})$ \\
\hline COC & 51 & 1 & 26 & $\begin{array}{l}304,1 \rightarrow 182,0^{\mathrm{a}} \\
304,1 \rightarrow 105,1\end{array}$ & 39 & 10 \\
$\mathrm{BE}$ & 51 & 5 & 20 & $290,1 \rightarrow 168,1^{\mathrm{a}}$ & 25 & 4 \\
& & & & $290,1 \rightarrow 105,0$ & 41 & 4 \\
$\mathrm{COE}$ & 26 & 4.5 & 14 & $318,1 \rightarrow 196,2^{\mathrm{a}}$ & 23 & 4 \\
& & & & $318,1 \rightarrow 105,3$ & 55 & 4 \\
COC-d3 & 16 & 5 & 22 & $307,1 \rightarrow 185,1^{\mathrm{a}}$ & 25 & 4 \\
BE-d3 & 16 & 4.5 & 98 & $293,1 \rightarrow 171,1^{\mathrm{a}}$ & 25 & 4 \\
COE-d3 & 11 & 5 & 28 & $321,1 \rightarrow 199,1^{\mathrm{a}}$ & 27 & 4 \\
\hline
\end{tabular}

${ }^{\mathrm{a}}$ Transition used for quantification. DP: declustering potential, EP: entrance potential, CEP: collision cell entrance potential, CE: collision energy, CXP: collision cell exit potential, RT: retention time.

The preparation of the samples analyzed in Brazil was identical to those sent to Spain, except for the pre-concentration step. After elution of the analytes with $6 \mathrm{~mL}$ of methanol and the addition of internal standards, the eluates were then evaporated under vacuum in a parallel evaporator Syncore Analyst (Buchi) to a final volume of $1.5 \mathrm{~mL}$. Table S3 shows the parameters of the analytical curves constructed for quantification of the selected analytes by liquid chromatography coupled to triple-quadrupole mass spectrometry (LC-QqQ), as well as limits of detection and quantification.

Table S3. Parameters of the analytical curves and limits of determination and quantification for the investigated analytes determined by LC-QqQ.

\begin{tabular}{|c|c|c|c|c|c|c|c|c|}
\hline Analyte & IS & $\begin{array}{l}\text { Working } \\
\text { Range }\end{array}$ & Analytical Curve & $\mathrm{R}^{2}$ & LODi & LOQi & LODm* & LOQm* \\
\hline & & $\mu g L^{-1}$ & $y=a+b x$ & & $\mu g L^{-1}$ & $\mu g L^{-1}$ & $n g L^{-1}$ & $n g L^{-1}$ \\
\hline $\mathrm{COC}$ & COC-d3 & $10-500$ & $y=0.001+0.006 x$ & 0.98 & 3 & 10 & 73 & 242 \\
\hline $\mathrm{BE}$ & BE-d3 & $10-500$ & $y=0.077+0.723 x$ & 0.99 & 3 & 10 & 71 & 233 \\
\hline $\mathrm{COE}$ & COE-d3 & $10-500$ & $y=0.012+0.092 x$ & 0.99 & 3 & 10 & 65 & 215 \\
\hline
\end{tabular}

COC: cocaine, BE: benzoylecgonine, COE: cocaethylene, IS: internal standard, a: linear coefficient, b: angular coefficient, LODi: limit of detection of the instrument, LOQi: limit of quantification of the instrument, LODm: method limit of detection, LOQm: method limit of quantification. * Limits calculated considering the efficiency of the method $(E f)$ and a concentration factor of 33 . 